\title{
EL VIAJE MARÍTIMO DEL MERCADER EN LOS AUTOS DE CALDERÓN ${ }^{1}$
}

\author{
Ana Suárez Miramón \\ Departamento de Literatura Española y Teoría de la Literatura \\ Facultad de Filología \\ Universidad Nacional de Educación a Distancia \\ C/ Senda del Rey, 7 \\ 28040 Madrid. España \\ anasuarezuned@hotmail.com
}

[Anuario calderoniano (ISSN: 1888-8046), 4, 2011, pp. 349-363]

El motivo de la navegación como forma de peregrinaje es uno de los más importantes del teatro de Calderón y en los autos tiene una abundante y variada representación. Permite expresar las coordenadas espacio-temporales de la existencia y la posibilidad de seguir dos direcciones muy opuestas, la del bien y la del mal. Pero además, la preferencia del autor por los motivos de la nave y del mar está también relacionada con su preocupación estética y teatral y estas escenas marinas proporcionaban movimiento, acción, y diferentes posibilidades

${ }^{1}$ Este trabajo se enmarca en el proyecto de autos sacramentales financiado por la Subdirección General de Proyectos de Investigación (FFI2008-02319 / FILO) cofinanciado por el FEDER. 
visuales. En su teatro sacramental se pueden distinguir dos grandes grupos de navegantes: los héroes míticos, como Jasón, Ulises, Orfeo y Teseo que por sus hazañas pueden servir de ejemplo para la aventura singular de cada hombre, y los mercaderes que, a diferencia de los héroes, solitarios, representan la dimensión social del hombre y, por tanto, su esfuerzo sirve igualmente de modelo de actuación. Junto a estos dos grupos, también los autos recogen otro grupo de navíos, las galeras, siempre negras, donde los forzados, a pesar de tener todo en su contra (tempestad, viento aquilón y furia del capataz), ofrecen siempre un ejemplo de esperanza ${ }^{2}$.

Hay que recordar que las metáforas de la navegación aplicadas a la vida humana se habían actualizado gracias a las ediciones de Séneca ${ }^{3}$ y el senequismo, como bien estudió Valbuena ${ }^{4}$, está presente en toda la obra del dramaturgo. Asimismo, obras como el Tratado de la tribulación, del Padre Ribadeneyra, ya habían utilizado los motivos marinos para representar la vida humana, de acuerdo con los textos sagrados. Por otra parte, la imagen de la nave, que contaba con una larga tradición pagana y cristiana, cobró una dimensión nueva a partir de Trento. Incluso el mítico navegante Ulises, ya había tomado tintes cristianos tras Natale Conti, Baltasar de Vitoria y Pérez de Moya.

Pero fue con la victoria de Lepanto cuando la representación de la nave sirvió para expresar el triunfo de la Iglesia militante. Precisamente B. L. de Argensola en su canción «A la nave de la Iglesia con motivo de la batalla de Lepanto $»^{5}$ (1634) relacionó la nave con el modelo iconográfico del Triumphus Ecclesiae, grabado realizado en 1601 por Filippo Thomasini, modelo asimismo de otro grabado editado en Milán bajo el título «Triunfo de la Fe y de la Ley de la Iglesia Católica certificada por sus quatro evangelistas y sus apóstoles y sus principales doctores contra toda energía y supersticiones del paganismo» (fuente, a su vez de varias obras posteriores) ${ }^{6}$. La disposición de la nave de Argensola y de su modelo es totalmente visual: lleva a Cristo en el

${ }^{2}$ Nos ocupamos en otro trabajo de las galeras y las naves míticas como complemento de este.

${ }^{3}$ Sobre todo en las cartas a Lucilio XIV, XXXI, XLV, LIII, LVI, CXXIII, pp. 393, $427,443,459,465$ y 881 .

${ }^{4}$ Valbuena Briones, 1965.

${ }^{5}$ Argensola, 1951, pp. 334-335.

6 Sebastián, 1981, pp. 154-155. 
mástil y sobre la vela se sitúa la Virgen mientras que la paloma del Espíritu Santo vuela en las alturas; Pedro lleva el timón y el arcángel San Miguel se mantiene en la proa mientras que los demás apóstoles se sitúan en el puente y los doctores de la Iglesia reman. Se completa el cuadro con la presencia de los herejes que atacan por un costado sin percatarse de la derrota que ya habían recibido sus compañeros.

Este ejemplo alegórico corroboraba la importancia del motivo a partir de Lepanto. El motivo también fue objeto de los más variados emblemas, jeroglíficos y proverbios que expresaban cómo la nave conduce al individuo desde su nacimiento, por el mar tempestuoso de los sufrimientos, hasta su muerte.

Con toda la carga simbólica que la nave había ido recibiendo no era difícil aceptar el correspondiente al camino de la vida interior. Puede afirmarse que era el espacio donde se podían integrar todos los valores concernientes al individuo, desde los líricos a los sociales (con los precedentes del «frágil leño» de Petrarca, «la nave de amores» de Gil Vicente, e incluso la sencilla barquilla de Fray Luis) o los religiosos (las Barcas alegóricas de Gil Vicente y la nave de la Iglesia) e incluso los simbólicos de la nave de los locos (El Bosco), además del cercano ejemplo cervantino del Persiles.

Entre los motivos iconográficos más importantes se han podido señalar ${ }^{7}$ el lienzo de La nave del estado religioso en el Monasterio de las Descalzas Reales, El Triunfo de la Iglesia, en el Museo parroquial de Daroca y, sobre todo, el magnífico grabado incluido en la Psalmodia eucharistica, sobre textos para el Corpus. El grabado cinco de la Psalmodia representa «la Carabela eucarística». Pero también, por su relación con el mar, los grabados del arca de Noé de la tradición exegético-arquitectónica y simbólico-hermética se habían actualizado, con Villalpando, Jerónimo del Prado y, sobre todo, con Athanasius Kircher que dedicó toda una serie de láminas al tema.

Un importante precedente para el arte calderoniano en torno a la navegación, que no se ha tenido en cuenta y nos parece fundamental, es la propia Galera real de don Juan de Austria que llevó a Lepanto. En su construcción no se escatimaron medios y se consiguió un ver-

${ }^{7}$ Ver Regalado, 1995, vol. II, pp. 47-48. Sebastián (1981, pp. 162-172) se ocupó del contenido de las doce láminas de Psalmodia y destacó su valor plástico y emblemático. 
dadero palacio flotante en forma de nave. Colaboraron importantes arquitectos y humanistas, como Mal Lara, para forjar toda una compleja alegoría. Este palacio flotante, estudiado por Aguilar ${ }^{8}$, tenía una espléndida decoración en el interior y en el exterior. En la proa presentaba escenas inspiradas en la Eneida y la Odisea, y en la popa acumulaba abundantes emblemas, la nave de Jasón con la conquista del vellocino además de varios fanales que representaban las virtudes teologales. La galera de Lepanto podría considerarse no sólo una imagen visual sino una realidad donde mito y cristianismo se habían fundido para representar lo que sería el triunfo de la $\mathrm{Fe}$, al mando del nuevo Jasón, don Juan de Austria. Con el éxito de Lepanto cobraron vida todos estos precedentes ideológicos y estéticos que después pudo manejar ágilmente Calderón en su teatro.

También la realidad de la época acercaba el tema a los espectadores. Entre los mercaderes marítimos, los de perlas eran los más arriesgados porque necesitaban enfrentarse a las profundidades del mar y superar grandes distancias para acceder a sus veneros. Un parecido riesgo comportaba el comercio de especies por el peligro turco y berberisco. En los dos casos, si el riesgo era grande también lo era la riqueza de quien conseguía regresar al puerto, cuyo espectáculo plasmó Lope en El arenal de Sevilla. Por su alto riesgo los mercaderes de piedras y especies, se han podido relacionar con los Caballeros de la Tabla Redonda en búsqueda del Santo Grial, y con los buscadores de la piedra filosofal, según estudió Mircea Eliade9 9

En los autos, el nombre que asume el mercader es, en muchos casos, Peregrino, aunque también se le nombra Príncipe, y su identificación con Cristo resulta evidente, de acuerdo con la tradición bíblica. Sin embargo, los propios textos calderonianos aclaran todos los valores. Así, en OM se refiere al Mercader como uno de los nombres que recibe Cristo; en MT se enseña el sentido completo de la alegoría marítima: Cristo es el mercader de piedras puras; la nave pilotada por Pedro equivale a la margarita porque proporciona pureza y luz a la Iglesia; en LM se refiere a las Indias como otro mundo, libre, no sometido a ningún peligro; en JF explicita el doble sentido de la nave: «que a dos luces representa / la nave del mar / y la nave de la Iglesia,

${ }^{8}$ Aguilar, 1987 y 1989.

${ }^{9}$ Herreros y alquimistas, 2001, pp. 80-100. 
/ pues viene de pan cargada", y en uno de sus últimos autos, DF, el Príncipe se refiere de forma concluyente al misterio eucarístico de la nave de trigo, que «trajo de lejanas tierras / el mercader, cuyo pan / tan alto misterio encierra, / que no sólo es pan de vida, / pero pan de vida eterna».

Calderón recoge así la tradición bíblica de la nave como representación de la Iglesia; la del mercader, asociado con Cristo, tanto de trigo, la más propia («es como la nave del mercader, que desde lejos trae pan», Proverbios, 31,14), como de perlas, que proviene de la parábola evangélica (Mateo, 13, 45-46): «También es semejante el Reino de los Cielos a un mercader que anda buscando perlas finas y que al encontrar una de gran valor va, vende todo lo que tiene y la compra».

Con estos elementos construye el dramaturgo piezas de gran interés dramático hasta conseguir la más lograda y compleja en NM. Desde las primeras referencias en VT (1634) hasta NM (1674), Calderón muestra su preferencia por este tema concreto dentro de los muchos ejemplos dedicados en su teatro a la navegación. Son muy numerosas las referencias a la nave cargada de trigo, o de trigo y perlas. Las posibilidades estéticas del motivo permitían establecer todo tipo de relaciones y correspondencias entre la realidad, el mito y la tradición bíblica, además de utilizar gran variedad de escenografias pues si la simbología del mar era extraordinariamente rica en lo conceptual, las posibilidades escénicas no eran menores. La aparición en el escenario de la nave o naves en diferentes situaciones (al borde del naufragio, llegando a puerto, o en el propio mar), con los atributos visibles propios de la guerra (banderas, insignias, toques de clarines y tambores) o de la paz (banderas blancas), la situación del navío en la Naturaleza (de día o de noche, en cuyo caso se potencian los elementos visuales), la incorporación de grupos humanos y la necesidad

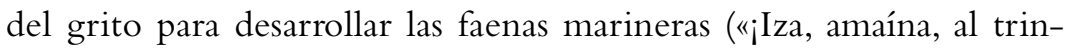
quete!») proporcionan todo un cúmulo de sensaciones que normalmente están acompañadas por otros sistemas paralelos (ecos que llegan por el aire, visiones que anuncian la tierra) y que todos unidos rodean al hombre en su soledad, en su miedo al naufragio (existencial) y a la muerte o le alientan a una empresa superior.

En el motivo de la nave del mercader no puede decirse que haya una evolución en su tratamiento pues ya desde las primeras obras el 
dramaturgo construye con los elementos marítimos piezas de gran interés. Lo que sí se percibe, a medida que utiliza el motivo, es la variedad de enfoques que maneja y la ampliación de las correspondencias y juegos de opuestos hasta lograr una obra dramática total.

En VT (1634) ya aparecen unidos el sentido simbólico y el escenográfico bajo una estructura de cuento folklórico donde el mercader del Oriente ofrece sus riquezas para curar a la infanta como alegoría de la riqueza espiritual desconocida. El dramaturgo sólo utiliza como escenografia la aparición de "un bajel en el mar», acompañado de música. Mediante el efecto de la luz (símbolo fundamental) su presencia misteriosa rompe la tristeza del ambiente invernal, anuncia el fin de la melancolía de la princesa y consigue ahuyentar a la muerte. Cuando toma tierra el Peregrino, la luz invade todo el escenario (con hachas encendidas) y el decorado verbal describe el barco a partir de los cuatro elementos («monte con alas», «águila del mar», «delfín del sol») y al peregrino como faro universal («luz de luz«). Se justifica entonces la nueva estación primaveral que deja atrás las sombras del invierno. Aunque la tierra a la que arriba el mercader es "fría» e "inhóspita» (El Mundo), al ofrecer su carga de las «dos especies», entre todas "las riquezas de Oriente» que había reunido, todo se transforma: la Infanta (Naturaleza) cambia su melancolía por la sonrisa, y el «alcázar» donde reside resulta un castillo encantado. Cambia su imagen sombría y recupera su aspecto primitivo, «celeste», al tiempo que la Infanta vuelve a sonreír y el frío invierno deja paso a la fértil primavera. La luz actúa simbólica y escenográficamente para proyectar la dualidad de cuanto se muestra en la obra: invierno, primavera; castillo sombrío, celeste, y melancolía, alegría.

En LE (1643) el dramaturgo intensifica los efectos de la luz sobre la escenografia y el texto. La nave del Mercader (de trigo) se presenta en escena, en un espacio totalmente iluminado, en el momento en que el Rey está hablando de su hijo, el Príncipe. La nave lleva en este caso a los esposos. Las didascalias implícitas sugieren en escena las «ondas» y se enseña su significado alegórico, «ansias y tribulaciones» al tiempo que se presenta una «bella nave» movida por los austros suaves «sobre la argentada tez» contra la que no tienen fuerza ni el aquilón ni el ábrego. Aquí el mercader viene a «cargar trigo de la casa de Belén». Por la forma de referirse a los Esposos, la escena naval resulta muy cercana a la de las entradas triunfales que tantas veces se 
pudieron contemplar en los puertos españoles con motivo de las bodas reales o las llegadas de príncipes, como la que el propio Calderón dramatiza en el LA (entre el archiduque Rodulfo y María) o las que refieren los cronistas o las conservadas en testimonios gráficos. Así, lo que ocurre en el escenario responde a un hecho cotidiano conocido por el espectador. El autor establece una secuencia entre el origen del trigo en Belén (nacimiento de Jesús) con el evangelio (Cristo mercader), y la relación con su esposa (Iglesia). Es decir, con la nave del mercader se dramatiza todo el proyecto divino de Cristo desde su nacimiento a partir de una técnica de imágenes diseminadas a modo de flash back conseguidas gracias al trigo.

Escénicamente SG (1644) aporta al motivo un gran espectáculo mediante la utilización de elementos duales, colores simbólicos y dinamismo teatral, como puede verse en la memoria de apariencias conservada:

armadas en dos bofetones, vuelan al tablado dos naves, según la capacidad que diere el teatro para el tamaño de ellas, y en cada una habrán de venir tres personas, por lo menos, éstas han de estar armadas, que puedan moverse a un lado y a otro; la una, ha de ser negra y todas las banderas de ella con las llamas pintadas en las ondas y vaso. La otra, ha de ser pintada de colores hermosos; las banderolas de ellas han de traer pintado el Sacramento, y en todos los remates cálices, y por fanal uno grande. La nave negra se ha de volver al lugar de donde salió y esconderse; la pintada ha de llegar hasta el cubo de la muralla, donde puedan desembarcar una o dos personas, que han de venir en ella, y ella se ha de volver a donde salió ${ }^{10}$.

Se produce un enfrentamiento en el escenario (como muestra la acotación que precede a la escena) entre la nave, cargada de trigo y «de colores alegres» y con «todas las banderas blancas» presididas por un fanal, y la negra, de "ondas de fuego y banderas negras». De forma espectacular y simbólica entablan un duelo en el tablado del que sale triunfante la blanca (dirigida por Pedro) que termina hundiendo a la negra (de la Apostasía).

Para un espectador del siglo XVII sin duda esa nave negra no resultaba lejana a la barca de Caronte (muerte); la blanca, además de las

${ }^{10}$ Calderón, El socorro general, ed. Arellano, 2001, pp. 9-10. 
referencias explícitas a la Iglesia y al maná como prefiguración de la Eucaristía (que se hacen en el texto), representa la vida. Pedro, piloto de la blanca, actúa de mercader de trigo «de la India del Oriente» que lleva el alimento a la Iglesia. La escenografia y el símbolo de la nave blanca abren y cierran el auto y adelantan, al final, la apoteosis eucarística representada por el desembarco de Pedro que porta «en lo alto un Cáliz con su Hostia en la mano», al tiempo que suenan las chirimías.

En VZ (1646) la nave del Príncipe (mercader de trigo) aparece en el tablado de forma espectacular; primero rompiendo «la niebla oscura» y dando vueltas entre música y salvas, en plena faena de echar el áncora y el esquife y entre gritos de los marineros. Aquí se establece la correspondencia entre la nave del «universal diluvio» y la del mercader. Se informa (Demonio) de las parábolas del «mercader... de pan» y de «la preciosa margarita» y al final, de nuevo aparece la nave en escena, dando varias vueltas, para anunciar la apoteosis con Gracia, sentada a una mesa "en forma de altar, con cáliz y hostia».

Un caso diferente, en cuanto que recoge un tema mitológico (el laberinto de Creta que en el auto se identifica con lo creado, a partir de la etimología de creata) pero desde su andadura humana, es el que ofrece LM (1647), con el protagonismo de Theos, fácil trascripción del héroe griego que mató al Minotauro y salió del laberinto, y etimología correspondiente a Dios, con lo que se justifica la doble naturaleza de Cristo. Como en SG, este auto se inicia con la extensa acotación que describe en este caso la nave de «forzados»: una "galera negra sobre ondas de llamas, pintados sus gallardetes de dragones, y en su proa una serpiente». La visión tétrica, de gran efectismo, se completa con el Furor en popa, la Envidia en el árbol mayor y al remo, de cautivo, el Hombre. Las palabras iniciales de Furor declaran su aspecto aterrador y apocalíptico («bestia de la mar») opuesto a la otra nave que aparece después, casi de forma impresionista, «sobre nubarrones azules y flámulas encarnadas, con Hostias y Cálices», en donde Theos preside la popa, la Caridad aparece en el árbol mayor y la Inocencia en la proa. Esta nave, "que nadar y volar a un tiempo sabe», orientada por una estrella de luz sólo comparable al sol, se presenta con toda la luminosidad posible para mostrar la belleza exterior e interior («intacta, pura, limpia, clara y bella») mientras la negra tiene las propiedades del abismo. Su procedencia también es opuesta: la negra 
viene del Poniente (ocaso y muerte) mientras la blanca llega del Oriente (nacimiento, vida, otro mundo) impulsada por el Austro.

El procedimiento utilizado para describir la galera se acerca a los testimonios de la época en la que se describían los peligros reales que comportaba el mar y que la tradición literaria ya había forjado (Cervantes, Góngora). Los forzados, condenados a galeras y separados de su patria y de su amor, se corresponden con las dos ausencias más profundas del hombre: su patria (el Paraíso) y el amor (Cristo), por lo que sólo la carga del mercader puede pagar el tributo al monstruo y así devolver a su patria y a su amor al hombre, de otro modo destinado a una muerte segura. La escenografia dual, apoyada por el juego de personajes binarios, se potencia en el texto por la luz inherente a esa doble condición del mercader (de trigo y perlas), que gracias a su riqueza puede enfrentarse a la nave de la muerte.

En SE (1648) la escenografia de la nave aparece casi al final del auto como colofón del doble sentido alegórico del auto. La nave que transporta «la piedra preciosa» (la Esposa), llega hasta un alcázar que es el mismo palacio donde les recibe un león en cuyo interior, al abrirse por medio, muestra un "cándido cordero». Un águila y una inocente paloma completan el bestiario alegórico de doble intencionalidad: la referida al cristianismo y a la casa de Austria. La nave del rey, Cristo, se identifica con «la nave del mercader» (Felipe IV) y «la perla preciosa», con la Iglesia y con Mariana de Austria.

En SC (1654) la Cizaña se refiere a esa nave del mercader como síntesis de los cuatro elementos, que «a un tiempo vuela y nada / sobre las espumas rizas» y que trae «de remotas provincias» el tesoro de las Indias. Además de la doble imagen del mercader (de trigo y de perlas) se introduce otra novedad simbólica. A partir del juego fónico entre Nave-ave ${ }^{11}$ se sugiere el himno medieval a María como estrella (Ave Maris stella) y se establece otra correlación entre María y semilla (con el doble sentido de 'origen' y 'palabra'). De ese modo identifica a la Virgen como luz pura e intacta que concibe el grano (Jesús) y la semilla (palabra de Cristo). Escénicamente la nave se presenta en el tablado con el Sembrador, "de galán, labrador» en una «noche buena» anunciando el trigo o palabra de Dios desde su origen en Belén.

11 En otro auto posterior QH (1672) utiliza el mismo juego fónico para referirse a Jael como prefiguración de María. 
Al final, la nave, presidida por un fanal y la cruz, cierra el auto representando la apoteosis eucarística tras un recorrido evangélico a partir del primer grano.

La singularidad de la nave del mercader se describe aún con más detalle en IN (1664). Aquí el misterioso bajel aparece en escena hacia la mitad del auto, interrumpiendo la acción anterior y, entre músicas y cantos, da "vueltas con algunos marineros» y aparece el Mercader, protagonista, «en la popa lo más lucido que pueda». La nave, por sus «blancas / flámulas de paz» y sus jarcias como «rojo nácar» muestra que se trata de la del mercader «que anda / buscando la margarita / preciosa». Según Plinio, las perlas ya eran muy apreciadas en la Antigüedad; se consideraban «principio y cumbre del precio de todas las cosas» ${ }^{12}$, y sólo podían lograrse en los mares indios, tras muchas dificultades, por lo que la perla blanca fácilmente se identificó después con la Eucaristía. Si a Orígenes se debe la identificación de la perla con Cristo por su luz, Mircea Eliade ${ }^{13}$ apuntó a su vez el carácter simbólico de las perlas para expresar el amor. En los autos, la presencia de la doble mercancía en las naves (trigo o pan eucarístico) y margarita (amor de Cristo) potencia el gran valor del amor. Calderón contaba además con el precedente bien explícito de Lope, La margarita preciosa, la «mejor joya del alma».

En IN, la hermosa nave se abre paso llena de luz y «llega a soplos de austros y de auras» "con el alba». Llega «del Ofir», de «trigo cargada», para abastecer al mundo. De nuevo se unen los dos símbolos, la perla y el trigo, de modo que la Culpa no puede reprimir su enojo («ambas señas son malas / para mí, pues margarita / o trigo me afligen ambas») mientras que Gracia se muestra feliz. El mercader trata de «enseñar al mundo» su "eterna sabiduría» para aliviar las desgracias. Abandona su travesía y desembarca para actuar como abogado del hombre cuando escucha las voces de Gracia y Culpa. Al final, tras anunciar que orienta su nave de regreso al paraíso, embarca al hombre en ella y él se queda en el jardín. La escenografía de la nave vuelve a utilizarse como apoteosis sacramental al final. Lo interesante de este final es su correspondencia con la estampa sexta de la Psalmodia eu-

${ }^{12}$ En su Historia natural recuerda la dificultad de encontrar una perla blanca (Libro IX, cap. XXV), p. 467.

13 Eliade, 1952, pp. 195-198. 
charistica ${ }^{14}$, donde aparece Cristo en el jardín, como imagen del nuevo paraíso en la tierra instaurado aquí por el mercader.

Pero es en NM (1674) donde se encuentra desarrollada toda la imaginería simbólica correspondiente a la nave del hombre que pugna por hallar su heroicidad. Como muy bien ha estudiado Arellano ${ }^{15}$, aquí están sintetizados todos los recursos de estilo (antítesis, estructuras simétricas, elementos duales) y las metáforas más utilizadas por el autor, así como los procedimientos y conceptos que se encuentran diseminados por otros autos (maná como prefiguración de la Eucaristía, nave labrada, belén como depósito de trigo, etc.). Además, y gracias a la memoria de apariencias conservada, se puede recrear la vitalidad de la puesta en escena del tema de acuerdo con los cuatro carros, dos de ellos ocupados por naves. Con independencia del gran simbolismo cristiano, estéticamente la obra revela, desde las indicaciones del autor, la consciente disposición de elementos antagónicos representados por las naves y cada uno de sus aparejos. Así, un primer carro es

una nave, rica y hermosa, adornada de sus jarcias y velas; el farol ha de ser un cáliz grande con su hostia y en su proa un serafín; sus flámulas y gallardetes blancos y encarnados [...] En su árbol mayor ha de tener una elevación en que pueda subir hasta el tope una persona

Mientras el otro "ha de ser una nave negra con un dragón en la proa y por farol un árbol, a cuyo tronco ha de estar enroscada una culebra. Sus banderolas han de ser negras y pajizas; ha de tener su elevación, su torno y su escalera, y en los gallardetes, pintados áspides». El primer escenario que aparece es «una marina con una nube y un peñasco", y el mismo escenario vuelve a aparecer, hacia la mitad del auto, pero ya junto a la marina, hay «una gruta con rejas».

Como en SG, la primera aparición corresponde a la nave negra y desde la acotación inicial se intensifican sus atributos visuales negativos mediante la «espada, plumas y bengalas» que porta el patrón de la nave, Culpa. Se añaden asimismo sensaciones auditivas ("suena el clarín») e incluso táctiles, como recoge la descripción del ambiente («helados carámbanos», «violento Aquilón»), para definir el carácter

${ }^{14}$ Ver Sebastián, 1981, p. 167.

15 Arellano, 1996. 
bélico y monstruoso de su misión. Así se consigue crear un "monstruo marino" cuya velocidad asusta hasta a las propias águilas. Pero su llegada a tierra aún es más negativa por su discurso amenazante. Allí busca a sus secuaces (Mundo, Demonio y Lascivia) y descubre a un Hombre dormido en un peñasco, quien desvela sus deseos gracias al procedimiento de visualización conceptual, y a «otro hombre» distinto, "vestido de armenio, dormido». Este Mercader prepara una nave pilotada por Amor y dirigida a Oriente por el Austro para descubrir el «tesoro escondido» o "preciosa margarita». En la acotación, «aparece en la marina la nave blanca» (como la de Argos, en DJ, que va a la conquista del vellocino de oro), acompañada del sonido del «clarín, y dando vuelta la nave, se ve en ella el Mercader, y otros, de marineros, y el Amor». Se entabla una competición entre las dos y aunque la negra persigue a la blanca, ésta puede volver sin problemas mientras la negra se hunde poco antes de tomar puerto.

Todo el juego de oposiciones y elementos contrarios se basa aquí en aparentes sensaciones que encubren conceptos simbólicos. Incluso la irrupción en escena de la nave representa también la violencia con que el ser humano se enfrenta a la vida. Así, mientras la nave negra sugiere la muerte y su carácter monstruoso simboliza la fuerza cósmica más instintiva, la blanca representa la luz de la inmortalidad, y la estrella que le sirve de guía, el símbolo del espíritu siempre vivo (gracias a María, estrella) a pesar del imperio de la noche. La ambientación es asimismo antagónica: al frío de muerte de la negra se opone la bonanza agradable de la blanca y, frente a los atributos agresivos de la primera, pilotada por Culpa, se alzan los sonidos armoniosos de la blanca y el fanal iluminador de la paz, guiada por el piloto Amor. Las correspondencias didácticas y religiosas se hacen evidentes y quedan corroboradas por las citas bíblicas incluidas en los símbolos utilizados (Culpa, Amor, cáliz, serafín, culebra, áspid).

Se puede ver en este auto (y en los anteriores donde aparecen las naves negras) el precedente estético y simbólico de la ópera El holandés errante $^{16}$. En ella Wagner actualizó el drama del hombre que lleva a sus espaldas «el dolor del mundo» y que sólo puede paliar el amor. Wagner confeccionó una tragedia que no estaba lejos de las visiones saturninas de las negras naves calderonianas y de sus oponentes blancas. A

\footnotetext{
${ }^{16}$ Ver Rull, 2009.
} 
partir de una maravillosa escenografia pictórica y teatral centrada en la visión de la naturaleza marítima (la tempestad, la nave y la costa) el músico y libretista narra la leyenda del holandés condenado a vagar por los mares en busca de un puerto para el reposo, nostalgia de un absoluto o paraíso al que desea volver. En el fondo El holandés plantea el problema del libre albedrío y la disposición del hombre para descubrir los valores superiores que se derivan de los sentimientos más nobles. El tema de la «redención por amor», que a partir de esta obra está presente en el resto de la creación wagneriana, muestra asimismo la relación con los personajes heroicos calderonianos que sobrepasan las aspiraciones meramente terrenales.

En conclusión, la peregrinación marítima del mercader resulta en Calderón un viaje épico pero también un viaje mítico y místico en cuanto que recupera el valor de la aventura con el peligro del abismo, del laberinto del mundo y del cosmos; trata de encontrar un perdido centro divino que se corresponde con la blanca mercancía (perlas y trigo), y muestra cómo un mercader bien experimentado en arriesgar su vida vuelve al puerto para ofrecer lo obtenido. El que el viaje sea por agua, símbolo de todas las posibilidades de la existencia, permite visualizar el roce constante entre el abismo y la trascendencia, que apunta desde el principio a la necesidad de regeneración, presente en todas las religiones, y fundamentalmente en la cristiana. Gracias a la nave del mercader se actualiza el tema de la redención cristiana y se experimenta, teatralmente, con todas las sensaciones, movimientos, color, escenarios variados, sugerencias y elementos simbólicos que, sin duda mantendrían en contante tensión al espectador. 


\section{Bibliografía}

Aguilar García, M. D., «La nave como palacio flotante: la galera real de D. Juan de Austria en Lepanto", en El barco como metáfora visual y transmisión de formas. Actas del Simposio Nacional de Historia del Arte, Málaga, Universidad de Málaga, 1987, pp. 339-362.

- «El barco como objeto artístico y viaje alegórico: la galera real de Lepanto», en Espacio, Tiempo y Forma, Serie VII, 2, 1989, pp. 93-114.

Calderón de la Barca, P., (DF), La divina Filotea, ed. L. Galván, Kassel, Reichenberger, 2006.

- (DJ), El divino Jasón, ed. I. Arellano y Á. L. Cilveti, Kassel, Reichenberger, 1992.

- (IN), La inmunidad del sagrado, ed. J. M. Ruano de la Haza y otros, Kassel, Reichenberger, 1997.

- (JF), El jardín de Falerina, ed. L. Galván y C. Mata, Kassel, Reichenberger, 2007.

- (LA), El lirio y la azucena, ed. V. Roncero, Kassel, Reichenberger, 2007.

- (LE), Llamados y escogidos, ed. I. Arellano y L. Galván, Kassel, Reichenberger, 2002.

- (LM), El laberinto del mundo, ed. J. M. Escudero, Kassel, Reichenberger, en preparación.

- (MT), El maestrazgo del toisón, en Obras completas III. Autos sacramentales, ed. Á. Valbuena Prat, Madrid, Aguilar, 1991, $2^{\text {a }}$ ed., $2^{\text {a }}$ reimp.

- (NM), La nave del mercader, ed. I. Arellano y otros, Kassel, Reichenberger, 2001.

- (OM), Las Órdenes militares, ed. J. M. Ruano de la Haza, Kassel, Reichenberger, 2005.

- (SC), La semilla y la cizaña, en Obras completas III. Autos sacramentales, ed. Á. Valbuena Prat, Madrid, Aguilar, 1991, $2^{\mathrm{a}}$ ed., $2^{\mathrm{a}}$ reimp.

- (SE), La segunda esposa y triunfar muriendo, ed. V. García Ruiz, Kassel, Reichenberger, 1993.

- (SG), El socorro general, ed. I. Arellano, Kassel, Reichenberger, 2001.

- (VT), El veneno y la triaca, ed. J. M. Escudero, Kassel, Reichenberger, 2000.

- (VZ), El valle de la Zarzuela, en Obras completas III. Autos sacramentales, ed. Á. Valbuena Prat, Madrid, Aguilar, 1991, $2^{\mathrm{a}}$ ed., $2^{\mathrm{a}}$ reimp.

Argensola, B. L. de, Poetas líricos de los siglos XVI Y XVII, ed. A. de Castro, Madrid, Atlas, 1951, vol. II.

Eliade, M., «Le mythe de la perle», en Images et simboles, Paris, Gallimard, 1952.

- Herreros y alquimistas [1959], Madrid, Alianza Editorial, 2001.

Plinio, C., Historia natural, Madrid, Visor, 1999. 
Regalado, A., Calderón. Los orígenes de la modernidad en la España del Siglo de Oro, Barcelona, Destino, 1995, 2 vols.

Rull, E., «El teatro mitológico de Calderón y el drama wagneriano (I)», en En buena compañía. Homenaje a Luciano García Lorenzo, ed. J. Álvarez Barrientos y otros, Madrid, CSIC, 2009, pp. 629-637.

Sebastián, S., "El arte al servicio del dogma», en Contrarreforma y Barroco, Madrid, Alianza Forma, 1981, pp. 145-194.

SÉneCA, Obras Completas, Madrid, Aguilar, 1943.

Valbuena Briones, Á., "Senequismo», en Perspectiva crítica de los dramas de Calderón, Madrid, Rialp, 1965, pp. 18-34. 